\title{
Dislocation of the Hip: A Review of Types, Causes, and Treatment
}

\author{
Kwesi Dawson-Amoah, BS, ${ }^{1}$ Jesse Raszewski, BS, MBS, ${ }^{2}$ Neil Duplantier, MD, ${ }^{3}$ Bradford Sutton Waddell, MD $^{3}$ \\ ${ }^{1}$ Rutgers Robert Wood Johnson School of Medicine, New Brunswick, NJ ${ }^{2}$ Alabama College of Osteopathic Medicine, Dothan, AL \\ ${ }^{3}$ Department of Orthopedic Surgery, Ochsner Clinic Foundation, New Orleans, LA
}

\begin{abstract}
Background: Dislocation of the hip is a well-described event that occurs in conjunction with high-energy trauma or postoperatively after total hip replacement.

Methods: In this review, the types, causes, and treatment modalities of hip dislocation are discussed and illustrated, with particular emphasis on the assessment, treatment, and complications of dislocations following total hip replacement.

Results: Hip dislocations are commonly classified according to the direction of dislocation of the femoral head, either anterior or posterior, and are treated with specific techniques for reduction. Generally, closed reduction is the initial treatment method, usually occurring in the emergency room. Bigelow first described closed treatment of a dislocated hip in 1870, and since then many reduction techniques have been proposed. Each method has unique advantages and disadvantages. Anterior hip dislocation is commonly reduced by inline traction and external rotation, with an assistant pushing on the femoral head or pulling the femur laterally to assist reduction. Posterior hip dislocations are the most common type and are reduced by placing longitudinal traction with internal rotation on the hip.

Conclusion: Patients with hip dislocations must receive careful diagnostic workup, and the treating physician must be well versed in the different ways to treat the injury and possible complications. Timely evaluation and treatment, including recognizing the potential complications, are necessary to offer the best outcome for the patient.
\end{abstract}

Keywords: Dislocation, hip, reduction, total hip arthroplasty

Address correspondence to Bradford Sutton Waddell, MD, Department of Orthopedic Surgery, Hospital for Special Surgery, 535 East 70 th St., New York, NY 10021. Tel: (212) 606-1000. Email: brad.waddell1@gmail.com

\section{INTRODUCTION \\ Anatomy}

The hip is a ball-and-socket joint that is inherently stable because of its bony geometry and strong ligaments, allowing it to resist significant increases in mechanical stress. Anatomic components contributing to the hip's stability include the depth of the acetabulum, the labrum, joint capsule, muscular support, and surrounding ligaments. ${ }^{1}$ The major ligaments stabilizing the joint from directional forces include the iliofemoral ligament located anteriorly and the ischiofemoral ligament located posteriorly. Because the anterior ligaments are stronger, trauma to the hip commonly presents as a posterior dislocation when discovered $(90 \%$ of cases). ${ }^{2,3}$ Dynamic muscular support includes the rectus femoris, gluteal muscles, and short external rotators. ${ }^{3}$ An understanding of the vasculature is important because trauma to the hip can displace the femoral head and interrupt the blood supply, leading to avascular necrosis (AVN). Branches from the external iliac artery form a ring around the neck of the femur, with the lateral femoral circumflex artery going anteriorly and the medial femoral circumflex artery going posteriorly. ${ }^{1}$ The major blood supply to the femoral head is the medial femoral circumflex artery. ${ }^{2-5}$

\section{Causes}

Dislocations of the hip can be classified as congenital or acquired. Congenital dislocations result from the physiologic position of the fetus in utero pressed against the abdominal wall of the mother, with the additional component of the posterior force acting against a dysplastic hip joint in flexion. ${ }^{6}$ Both factors together result in a partial or complete dislocation in a neonate; however, this topic is beyond the scope of this paper. Acquired hip dislocations are either native dislocations or dislocations after total hip replacement (Figure 1). ${ }^{3,7-10}$ The majority of native hip dislocations result from motor vehicle collisions. ${ }^{4}$ In the typical scenario, the patient is sitting with the hip in flexion, and upon impact, the thigh hits the dashboard, sending a posteriorly directed force to the joint and causing a posterior dislocation. ${ }^{4,11}$ The most common acquired dislocation is hip dislocation that occurs within the first 3 months following total hip replacement. ${ }^{12}$ This scenario occurs when the patient reaches 


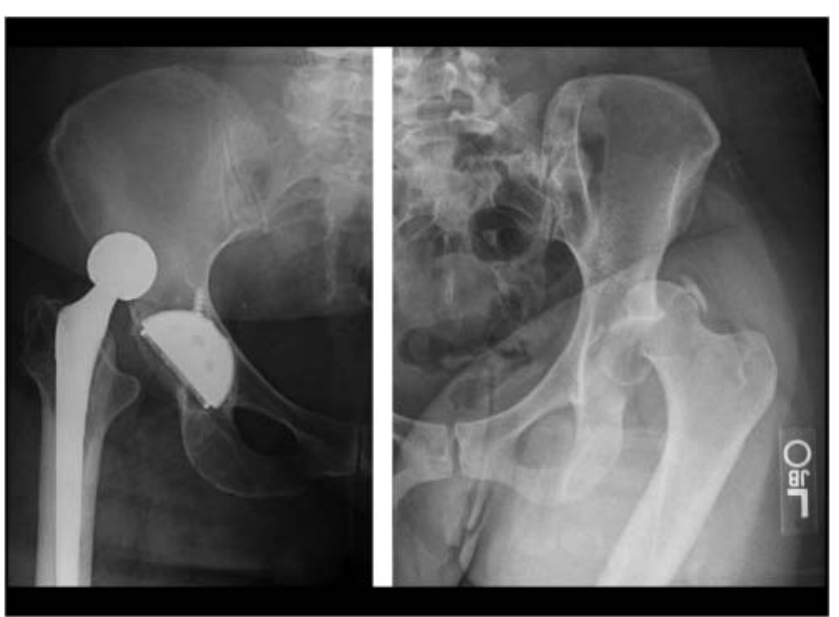

Figure 1. X-rays illustrate post total hip replacement dislocation (left) and native hip dislocation (right).

the extremes of the prosthetic range of motion and the femoral neck levers on the acetabular cup, allowing the femoral head to escape from the acetabulum. Other common conditions that can lead to postoperative dislocations include laxity or soft-tissue incompetence surrounding the hip joint (ie, revision), incorrect positioning of prosthetic components, and neuromuscular disorders (eg, Parkinson disease) ${ }^{9}$

Predisposing factors for hip dislocations continue to rise. ${ }^{2,10,13,14}$ A 2014 report by the National Highway Traffic Safety Administration noted more than 2.3 million motor vehicle-related injuries occurred among predominantly younger drivers, an increase of $1.1 \%$ since $2013 .{ }^{15}$ A summative 1982 study by Woo and Morrey found a dislocation rate of $3.2 \%$ in more than 10,000 primary total hip replacement procedures. ${ }^{16}$ Other studies have reported dislocation rates as high as $10 \%$ for primary procedures and up to $28 \%$ for revision. ${ }^{10,12,17,18}$ By 2030 , the number of procedures is projected to increase $174 \%$ for primary hip replacements and $137 \%$ for revisions, suggesting that the number of patients who present with dislocations may also increase. ${ }^{13,17}$ The assessment, treatment, and complications of dislocations following total hip replacement are the primary emphasis of this review.

\section{ASSESSMENT}

Hip dislocations are time-sensitive medical emergencies that must be treated promptly to prevent permanent complications. ${ }^{19,20}$ Because of the traumatic nature of native hip injuries, taking the first steps in advanced trauma life support is critical to stabilize the injured patient. If the injury is low energy, a complete survey should still be performed to rule out fragility injuries or concomitant injury. A complete history and physical will clue the health professional to the cause of dislocation (post total hip replacement vs native) and the type (posterior vs anterior). ${ }^{2-4,21} \mathrm{~A}$ physical examination is crucial in the workup of a suspected hip dislocation. Soft-tissue injuries and ipsilateral lower limb injuries can prevent a successful closed reduction. Recognizing these concomitant injuries early is important because they may be exacerbated by closed reduction. Injury to the ipsilateral knee must be ruled out as well, because the knee is used as the lever in reducing the hip. ${ }^{22}$
Patients with a posterior dislocation present with a limb adducted, flexed, internally rotated, and shortened. Anterior hip dislocations are classified as either superior-anterior (pubic) or inferior-anterior (obturator). ${ }^{7,23,24}$ Pubic-type dislocations result from abduction, extension, and external rotation of the hip. Obturator-type dislocations result from abduction, flexion, and external rotation of the hip., ${ }^{4,25} \mathrm{~Pa}$ tients with anterior dislocations may have a palpable femoral head in the femoral triangle in contrast to a palpable femoral head in the gluteal area with posterior dislocations. ${ }^{2}$

\section{Native Dislocation Assessment}

High-energy trauma can cause secondary injuries, so after the history and physical, a provider must complete a neurovascular examination prior to attempting closed reduction. While rare, the most common nerve complications associated with posterior hip dislocations are sciatic nerve injury (10\% of cases), and less commonly, peroneal branch and lumbosacral root injury. 2,3,5,26 To test for sciatic nerve damage, assess if dorsiflexion of the ankle and toes is impaired. ${ }^{5}$ Neurovascular complications associated with anterior dislocations are also rare but include injury to the femoral nerve, artery, and vein..$^{2,3,5}$

Imaging is critical to confirm the diagnosis and rule out potential fractures. In almost all cases, the dislocation can be confirmed with an anteroposterior (AP) x-ray of the hip, but if the finding is vague, additional x-rays (frog-leg lateral, cross-table lateral, Judet views) can be taken as needed., ${ }^{2,5}$ Not only does an AP view confirm the cause and type of dislocation but can also show signs of lumbar injury and acetabular fractures. Normally, the femoral heads of both limbs should be equal in size and congruent within the acetabulum. ${ }^{5}$ On an AP x-ray, a posterior dislocation shows a smaller femoral head in the acetabulum as the bone is positioned further from the $x$-ray source and closer to the film. A lateral view should be used to confirm this finding. ${ }^{2}$ In an anterior dislocation, the femoral head appears larger than the unaffected hip because the bone is positioned closer to the $x$-ray source and further away from the film. ${ }^{3}$ Postreduction $x$-rays should be taken to confirm reduction, followed by a computed tomography (CT) scan in 1- to 3-mm cuts through the pelvis to show concentric reduction. ${ }^{2,3} \mathrm{CT}$ scans will also detect any loose fragments and occult fractures, especially of the femoral head or neck. ${ }^{2,27}$ Magnetic resonance imaging (MRI) has been used to supplement CT scans; however, the cost effectiveness of MRI and its ability to identify small bony fragments are debated. ${ }^{2,28}$

\section{Postoperative Prosthetic Dislocation Assessment}

Dislocations after total hip replacement are usually a result of low-energy trauma; however, high-energy dislocations occur and require a more detailed secondary survey. Prosthetic dislocations are a time-sensitive medical emergency. ${ }^{29}$ Although the protocol for treating postoperative dislocations has not yet been standardized, a 2014 report by Dargel et al presents a comprehensive treatment algorithm. ${ }^{12} \mathrm{~A}$ range of patient- and surgery-related risk factors can be associated with postoperative dislocations. The time since the primary/revision total hip replacement procedure may inform the physician if the precipitating factor was inadequate softtissue healing or prosthetic malposition (early dislocations) or prosthetic wear (late dislocations). Information necessary 
for a detailed history includes when the patient received the hip replacement, what approach was used, how the dislocation occurred, the number of previous dislocations, and patient compliance with postoperative range of motion restrictions. ${ }^{8}$ Further, questions about medical conditions (eg, Parkinson disease, multiple sclerosis, alcoholism) and previous surgeries are important because each condition is a potential risk factor that can precipitate dislocations through muscle weakness and imbalance. ${ }^{29}$ During the physical examination, the physician should assess neurovascular status, as well as the appearance of the affected limb and surgical incision scars that can alert the physician to the approach used. A good practice is to call for cultures, as an unrecognized infection may have caused the instability and dislocation. ${ }^{12,29}$

Diagnostic imaging of total hip replacement dislocations begins with AP and cross-table lateral x-rays of the hip. ${ }^{8,29}$ The position of the femoral component and acetabular version and inclination, along with changes in offset and leg length, will help guide the initial management through closed reduction. ${ }^{8}$ Other important factors include size of the femoral head and type of prosthetic that have been found to play a significant role in the rate of dislocation. A 2005 study of more than 20,000 total hip replacements found a significantly decreased rate of dislocation with the use of larger femoral heads. ${ }^{30}$ Stratified by femoral head size, dislocation rates were $3.6 \%$ for $28 \mathrm{~mm}, 4.8 \%$ for $26 \mathrm{~mm}$, and $18.8 \%$ for $22 \mathrm{~mm}^{8}$ Other studies have noted the effectiveness of even larger head sizes ranging from 28 to $40 \mathrm{~mm}^{31,32}$ Types of prosthetics include constrained liners and dual-mobility implants, each having advantages and disadvantages. ${ }^{33,34}$ Constrained liners are used in certain patients to maintain stability and can usually be identified by an extra circular ring of metal on the periphery of the polyethylene insert (Figure 2). The challenge with these prostheses is that in restricting motion, they tend to fail catastrophically, and dislocations can necessitate open reduction or revision. Closed reduction may be possible; however, the treating physician should recognize the reason the constraint failed, leading to the dislocation.

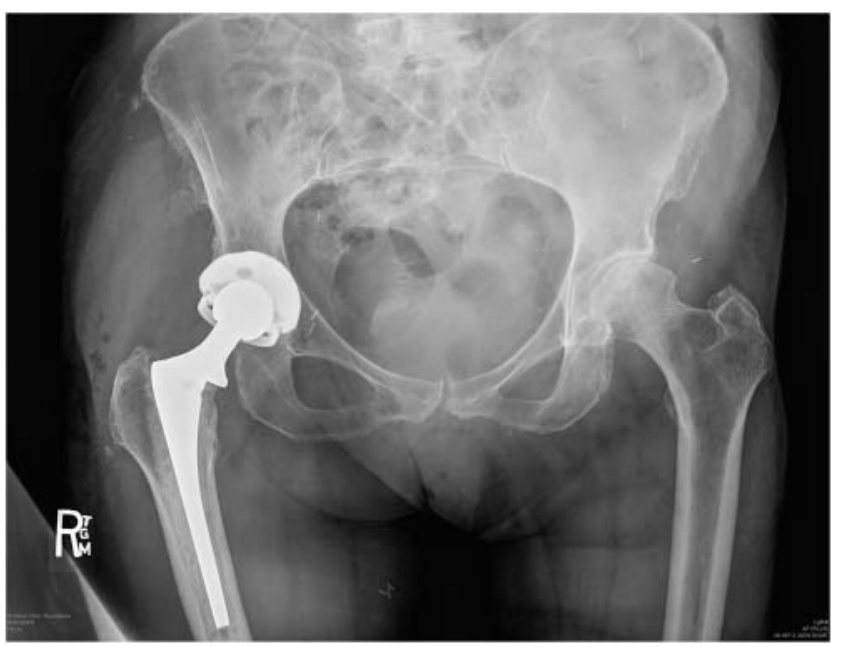

Figure 2. X-ray shows the constrained liner in total hip replacement. Note the metal ring in the polyethylene holding the femoral head inside the acetabulum.
Failure of the constraint could be attributable to component malposition or implant wear, both of which could necessitate revision. ${ }^{35}$ Dual-mobility implants are relatively new components (introduced in 2009) in the United States that provide additional range of motion of the hip joint prior to impingement and subsequent dislocation. ${ }^{14}$ Fixed femoral head implants normally have one articulation point, a small metal/ ceramic femoral head within an acetabular component. In dual-mobility implants, two articulation points are at play, with the first point of articulation between a small metal/ ceramic femoral head within a larger polyethylene femoral head, and a second point of articulation with the larger polyethylene femoral head and the acetabular component. When the small femoral head reaches the limit of its range of motion, the larger femoral head will then move which allows for an increased range of motion before impingement (Figure 3A). ${ }^{14,35,36}$ However, because of the additional bearing compared to fixed-bearing total hip replacement, a unique dislocation can occur known as an intraprosthetic dislocation (IPD) (Figure 3B). ${ }^{14,35}$ In an IPD, the larger polyethylene femoral head dissociates from the smaller femoral head. $^{35,36}$ Postreduction $\mathrm{x}$-rays can show what appears to be a successful reduction; however, in an IPD, the femoral head is eccentrically located in the acetabulum, and close evaluation reveals a halo in the soft tissue, representing the polyethylene that has dissociated (Figure 3B). Open revision is necessary to treat an IPD. Early treatment is necessary as instability will occur with the improper articulation of the small metal/ceramic femoral head on the much larger acetabular cup, and the metal/ceramic femoral head will damage the acetabular cup, necessitating its revision. ${ }^{35}$

A newly recognized phenomenon in patients who have had a hip replacement and then undergo lumbar fusion surgery is dislocation that occurs because of the change in sacral slope and pelvic tilt. This change can lead to a relative retroversion of the acetabulum and to instability of the hip. The lumbar spine must be investigated in cases of late dislocation. ${ }^{37,38}$

\section{TREATMENT}

As mentioned previously, all types of hip dislocation are time-sensitive emergencies that must receive prompt treatment. No more than 6 hours should elapse between presentation and reduction. Permanent complications and invasive procedures can become necessary if the hip is not reduced within the 6-hour window. ${ }^{2-4}$ Absent any contraindications such as fractures, IPD, or ipsilateral knee injury, a timely closed reduction can usually be performed under sufficient sedation in the emergency department. ${ }^{3,34}$

Native dislocations are the most time-sensitive dislocations, as prolonged dislocation of the native hip can have detrimental effects on the femoral head (AVN) and chondral surface (chondrolysis). ${ }^{3,4}$ Because of the potential for fracture if the patient's muscles remain active, Frymann et al recommend conscious sedation to reduce trauma to the hip and reduce the time to achieving reduction. ${ }^{39}$ On the other hand, administration of intravenous, general, or regional sedation has been proven to reduce complications and ease the modes of reduction in numerous studies. . $^{2,7,8,34,39}$

In postoperative total hip replacement dislocations, if the prosthetic components are adequately positioned, most patients $(67 \%)$ who undergo successful closed reduction will not experience another dislocation. ${ }^{8}$ Adequate sedation is 

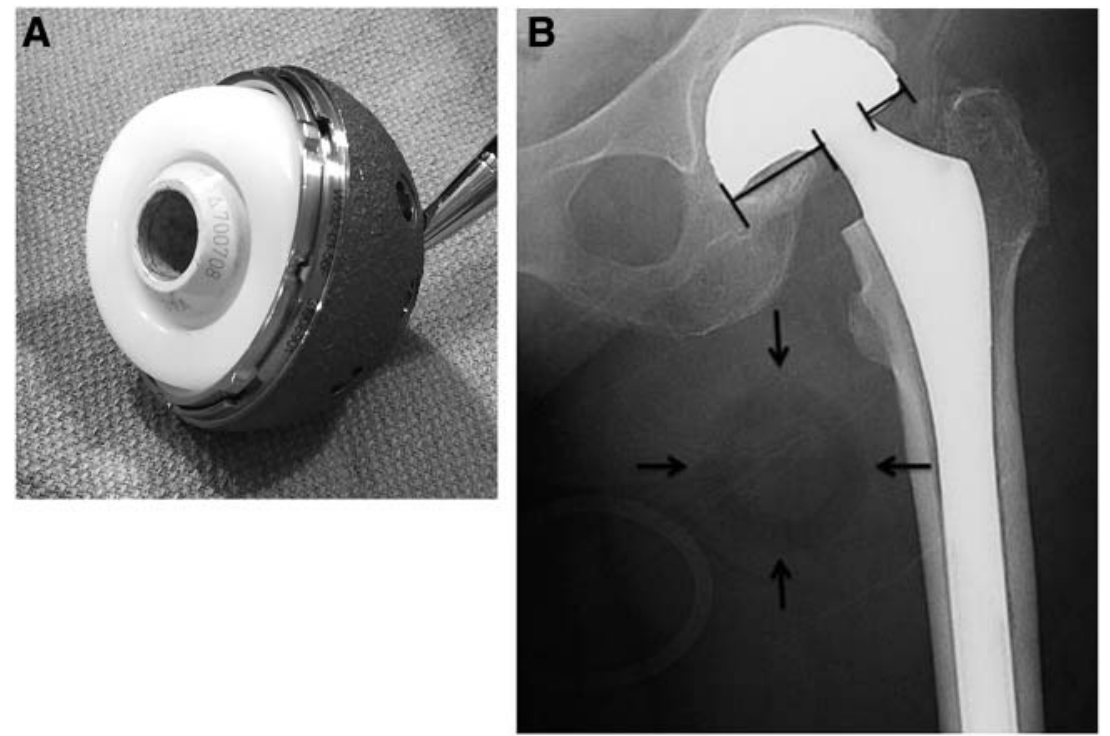

Figure 3. (A) Dual-mobility implant components include a small central metal or ceramic head joined to a larger polyethylene head within an acetabular cup. (B) X-ray shows the dislocated and uncoupled polyethylene head in the patient's soft tissue. Black arrows demarcating the "bubble sign" indicate the polyethylene head.

required to properly relax the muscles and reduce the risk of injuring the patient or physician. ${ }^{7,34}$ Adequate sedation also reduces the risk of repeated attempts at closed reduction that can damage the prosthesis or injure the patient. ${ }^{3}$

Bigelow first described closed treatment of a dislocated hip in 1870, and many reduction techniques have been proposed since then. ${ }^{7}$ Because closed reduction techniques require placing the patient in different positions (eg, prone, supine, lateral decubitus), the choice of technique should minimize further injury at the time of presentation. Although mastery of each technique is not mandatory, becoming proficient in a few techniques will aide in the flexibility of treatment when one approach fails to work. ${ }^{2,7}$ Posterior and anterior methods of reduction are described and illustrated below.

\section{Closed Reduction for Posterior Dislocations}

Allis Maneuver: The patient is in supine position with the physician standing above the patient. The physician applies inline traction on the ipsilateral leg, flexing the ipsilateral knee to $90^{\circ}$ while an assistant stabilizes the pelvis against the stretcher for countertraction. Gentle extension of the ipsilateral leg with external rotation as the hip reduces allows the femoral head to enter the acetabulum. An audible sound, or "clunk," is heard with successful reduction (Figure 4). 4,7,40

Bigelow Maneuver: With the patient in supine position, the physician grasps the ipsilateral limb at the ankle with one hand and places the free hand behind the knee. An assistant applies a downward force on the anterior superior iliac spine for countertraction. The physician applies inline longitudinal traction, flexing the patient's knee to $90^{\circ}$. As the limb reduces, the physician applies gentle extension, abduction, and external rotation for the femoral head to move into the acetabulum. Physicians should stand on the side of the bed while performing this maneuver to enhance safety (Figure 5). ${ }^{2,7,41}$
Lefkowitz Maneuver: The patient is in supine position, and the physician stands to the side of the affected limb. The physician places his/her flexed knee under the patient's ipsilateral knee in the popliteal fossa and his/her foot on the stretcher. With the patient's knee flexed over the physician's leg, the physician applies a gentle downward force on the leg until the hip is reduced (Figure 6). ${ }^{7,42}$

Captain Morgan Technique: The patient is supine, and the physician stands on the affected side. The pelvis is fixed and stabilized against the stretcher. The patient's hip and knee are flexed to $90^{\circ}$, and the physician places his/her flexed knee under the ipsilateral knee in the popliteal fossa. The physician grasps the ipsilateral ankle with one hand and places the free hand under the ipsilateral knee, applying an upward force by plantar flexing the foot until the hip is reduced. Although similar to the Lefkowitz maneuver, the Captain Morgan maneuver utilizes stabilization of the pelvis against

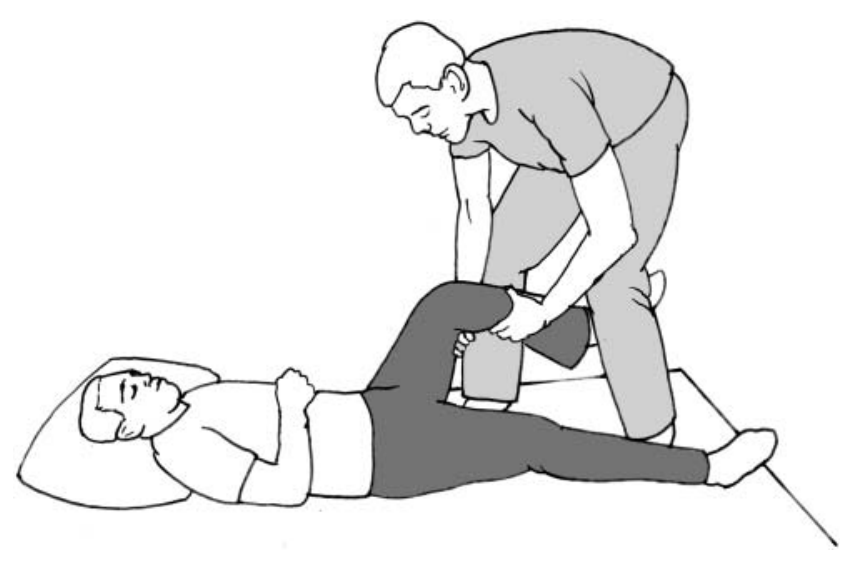

Figure 4. Allis maneuver. ${ }^{7}$ 


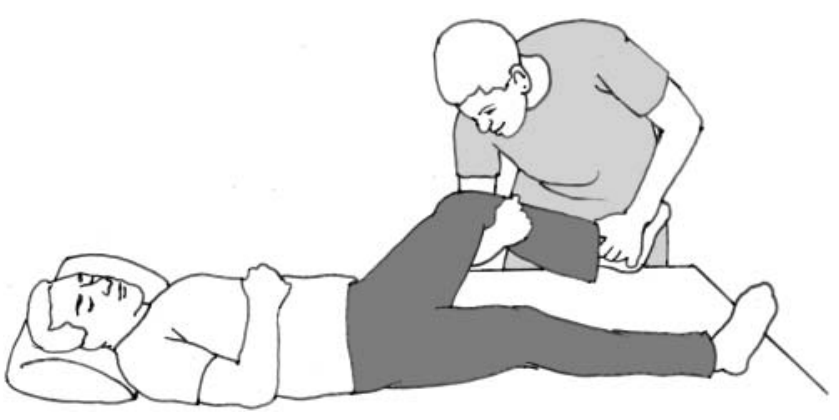

Figure 5. Bigelow maneuver. ${ }^{7}$

the stretcher and the free hand underneath the ipsilateral knee (Figure 7). ${ }^{7,43}$

East Baltimore Lift: The patient is supine. The physician stands on the affected side, and an assistant stands on the opposite side. The ipsilateral limb is flexed so the hip and knee are at $90^{\circ}$. With the physician and assistant facing the head of the bed, both place one arm underneath the knee of the ipsilateral hip, hooking their arms under the popliteal fossa and resting their hands on each other's shoulders. With the physician stabilizing the pelvis with a free hand, a second assistant applies a downward force while the physician and first assistant apply an inline upward force with extension of their knees. As the limb reduces, the physician can also apply adduction, abduction, and internal and external rotation using the ipsilateral ankle. If only 2 people are available, this technique can still be completed. The physician uses the arm closest to the patient's ipsilateral hip as the pivot and the other arm to grab the ipsilateral leg. The assistant stabilizes the pelvis while helping the physician apply inline traction to the ipsilateral limb by extending the legs until the hip is reduced (Figure 8). ${ }^{7,44}$

Howard Maneuver: The patient is supine, and both physician and assistant stand on the affected side. The ipsilateral hip is flexed to $90^{\circ}$. The assistant grasps the thigh and applies a lateral traction force. A second assistant stabilizes the pelvis while the limb reduces. If a second assistant is not available, the first assistant stabilizes the pelvis as the physician holds the ipsilateral lower leg by the knee. The physician applies inline traction with internal and external rotation until the hip is reduced (Figure 9)..$^{7,45}$

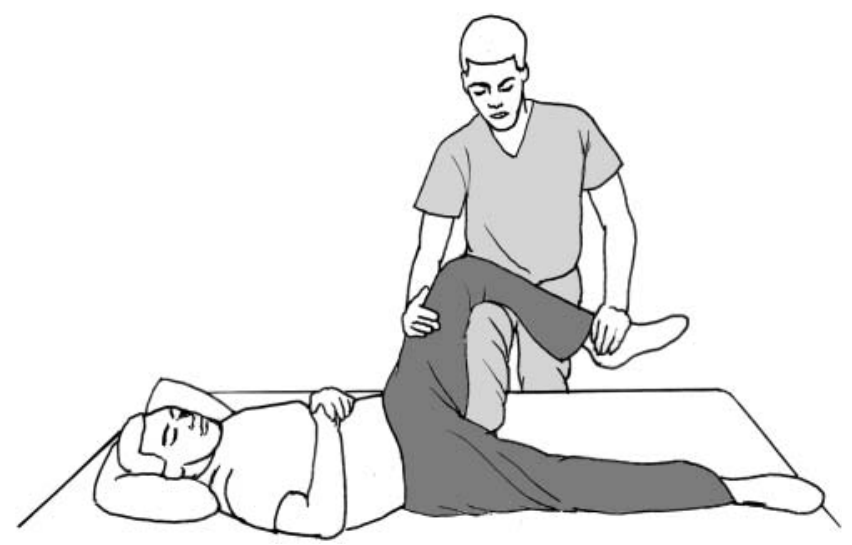

Figure 6. Lefkowitz maneuver. ${ }^{7}$

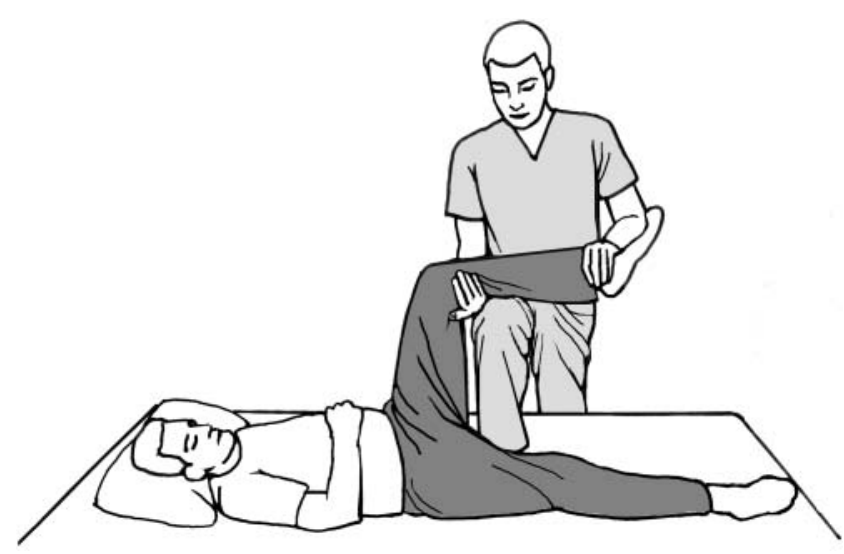

Figure 7. Captain Morgan technique. ${ }^{7}$

Lateral Traction Method: With the patient supine, the assistant wraps a cloth or his/her hands around the patient's ipsilateral inner thigh. The physician applies a longitudinal force along the femur with the knee extended while the assistant pulls on the cloth to apply lateral traction. As the limb reduces, internal rotation can be used if needed (Figure 10). 7,46

Piggyback Method: The patient is supine at the edge of the stretcher, and the ipsilateral hip is flexed to $90^{\circ}$. The physician places the patient's knee on his/her shoulders and using the shoulder as a fulcrum, applies a downward force on the tibia to create an anteriorly directed force at the hip until it is reduced (Figure 11). ${ }^{7,47}$

Tulsa Technique/Rochester Method/Whistler Technique: The patient is supine, and the physician stands on the affected side, placing the contralateral knee in $130^{\circ}$ of flexion. The physician places his/her arm under the ipsilateral knee so the leg is flexed over the forearm and uses the same hand to grasp the contralateral knee. With the free hand, the physician fixes the ipsilateral ankle against the stretcher and applies downward traction using the ankle along with internal and external rotation until the hip is reduced (Figure 12). ${ }^{7,21,46,48,49}$

Skoff Maneuver: The patient is in the lateral decubitus position with the ipsilateral limb facing up. The physician stands on the side the patient is facing. The limb is placed into $90^{\circ}$ of hip flexion, $45^{\circ}$ internal rotation, $45^{\circ}$ adduction, and $90^{\circ}$ of knee flexion. Lateral traction is provided as the assistant leans back in line with the femur. The physician then palpates the protrusion in the gluteal region and pushes the dislocated femoral head until the hip is reduced (Figure 13).., 50

Stimson Gravity Maneuver: The patient is prone, with both hip and knees at $90^{\circ}$ of flexion over the edge of the stretcher. With an assistant stabilizing the pelvis, the physician holds the ipsilateral knee and ankle and applies a downward pressure to the limb distal to the knee until the limb is reduced. The physician can apply internal and external rotation to assist in reduction. Caution must be taken with this technique, as a sedated patient in the prone position must have his/her airway continually monitored. Further caution must be taken to prevent the patient from falling off the stretcher (Figure 14). $4,7,51$

Traction-Countertraction Maneuver: This technique is a modification of the Skoff lateral reduction maneuver and requires 2 people. The patient is in the lateral decubitus position with the ipsilateral limb facing up. An assistant moves the affected limb into $90^{\circ}$ of hip flexion, $45^{\circ}$ internal rotation, 
Dawson-Amoah, $\mathrm{K}$
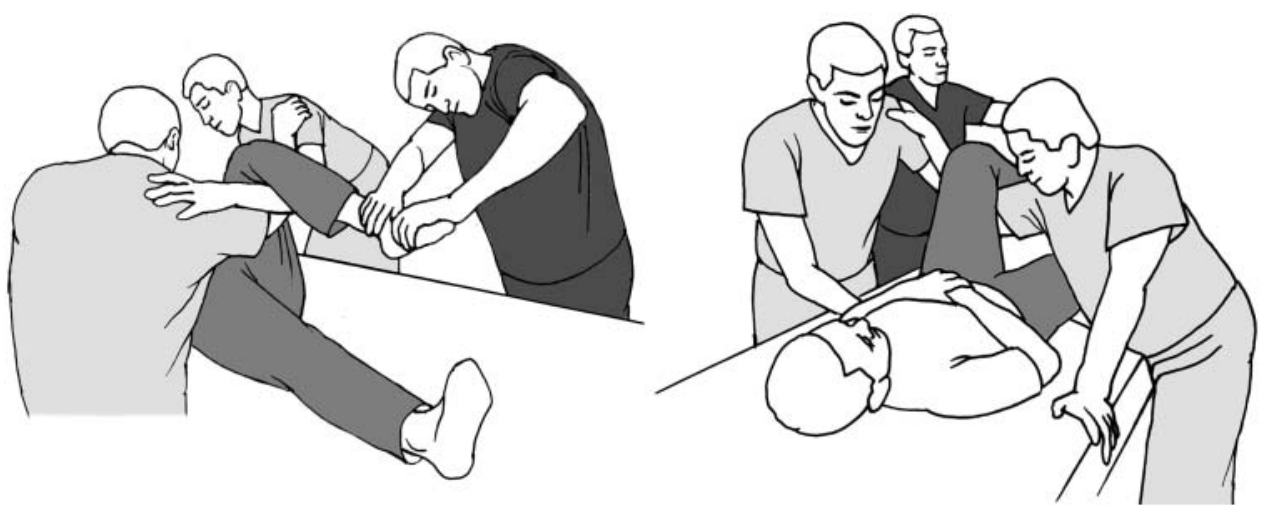

Figure 8. East Baltimore lift. ${ }^{7}$

$45^{\circ}$ adduction, and $90^{\circ}$ of knee flexion. Using hospital sheets knotted to form a loop, an assistant stands in the loop and places the strap through the patient's groin and over the iliac crest. A second loop is placed behind the ipsilateral knee, with the physician standing in the loop. The physician provides lateral traction in line with the femur by leaning back while using his/her free hands to manipulate the lower limb. Simultaneously, the assistant leans back to provide lateral traction against the loop, while using the heels of his/her hands to push on the deformity in the gluteal region until the hip is reduced (Figure 15). ${ }^{7,52}$

Flexion Adduction Method: With the patient supine, the physician stands on the contralateral side and lifts the ipsilateral leg to $90^{\circ}$ of flexion and maximum adduction. The physician applies traction in line with the femur while an assistant stabilizes the pelvis and pushes the head of the femur into the acetabulum until the hip is reduced (Figure 16). ${ }^{7,53}$

Foot-Fulcrum Maneuver: The patient is supine with the physician sitting at the foot of the bed. To reduce the risk of slamming the femoral head against the superior rim of the acetabulum during reduction, the physician gently maneuvers the affected limb to maximum allowed flexion to move the dislocated femoral head into a more posterior position. At the foot of the bed, the physician creates a fulcrum by placing his/her inner foot against the anterior surface of the ipsilateral ankle and placing the outer foot against the

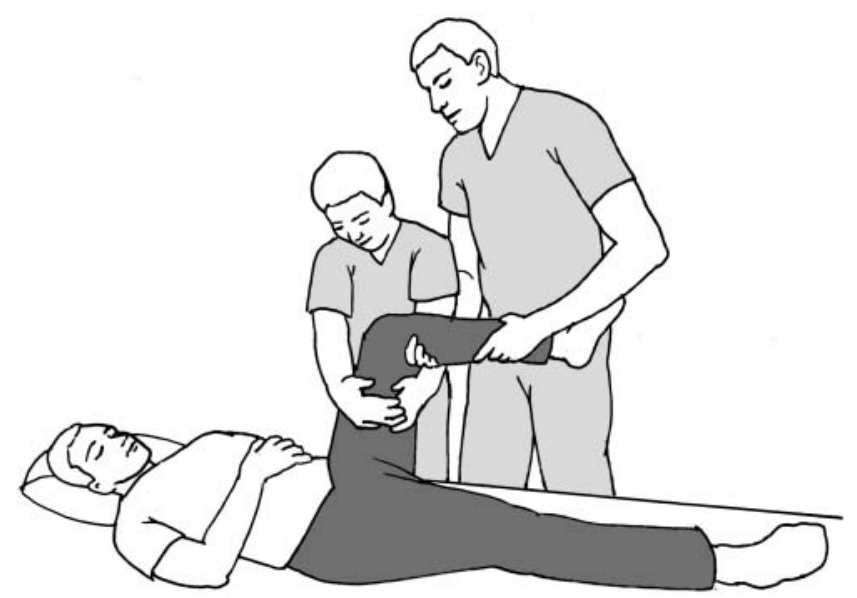

Figure 9. Howard maneuver. ${ }^{7}$ posterolateral hip to feel for the dislocation with the sole. The physician then applies longitudinal traction in line with the femur by grasping the ipsilateral flexed knee and leaning backward until the hip is reduced. Internal rotation can be applied as needed by leaning from side to side (Figure 17). ${ }^{7,10}$

Waddell Technique: This technique uses elements of the Allis and Bigelow maneuvers and is modified to protect the physician from back strain during reduction. This technique requires 2 people. With an assistant stabilizing the patient's pelvis against the stretcher, the physician climbs on the stretcher. The physician places the ipsilateral leg between his/her legs and puts his/her forearm underneath the knee for that limb to flex over the arm. To lock the limb safely in place, the physician rests his/her forearm across his/her knees so the elbow is on one knee and the hand on the other. With the ipsilateral knee close to the physician's chest, the physician maneuvers the hip to $60^{\circ}-90^{\circ}$ of flexion and the knee to $90^{\circ}$ of flexion. The physician applies traction on the femur by leaning backward, using his/her feet as a pivot and continuing until the limb is reduced, using adduction and internal rotation by leaning as needed (Figure 18). ${ }^{7}$

The authors prefer to use the Waddell technique for closed reduction of posterior dislocations. This technique reduces the stress on the treating physician's back by following Occupational Safety and Health Administration principles of keeping the heavy load close to the body and using the feet as a lever to apply inline traction to the patient's leg and hip. Furthermore, this technique allows the

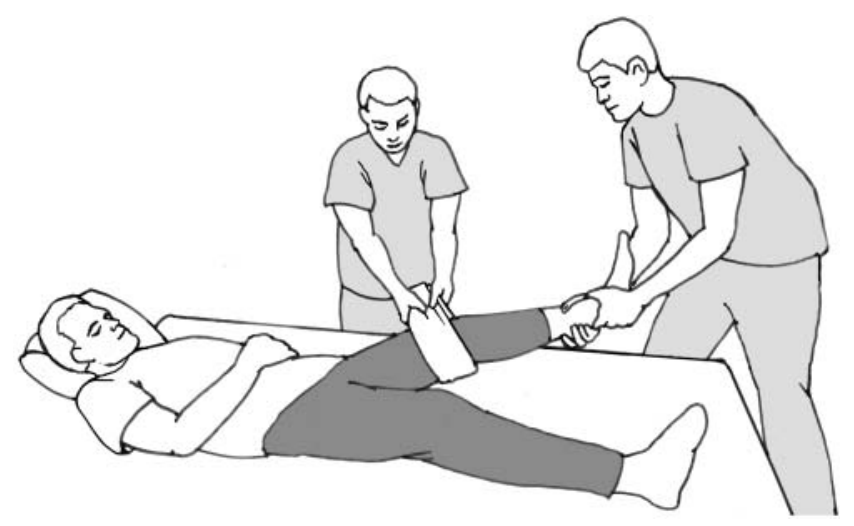

Figure 10. Lateral traction method. ${ }^{7}$ 


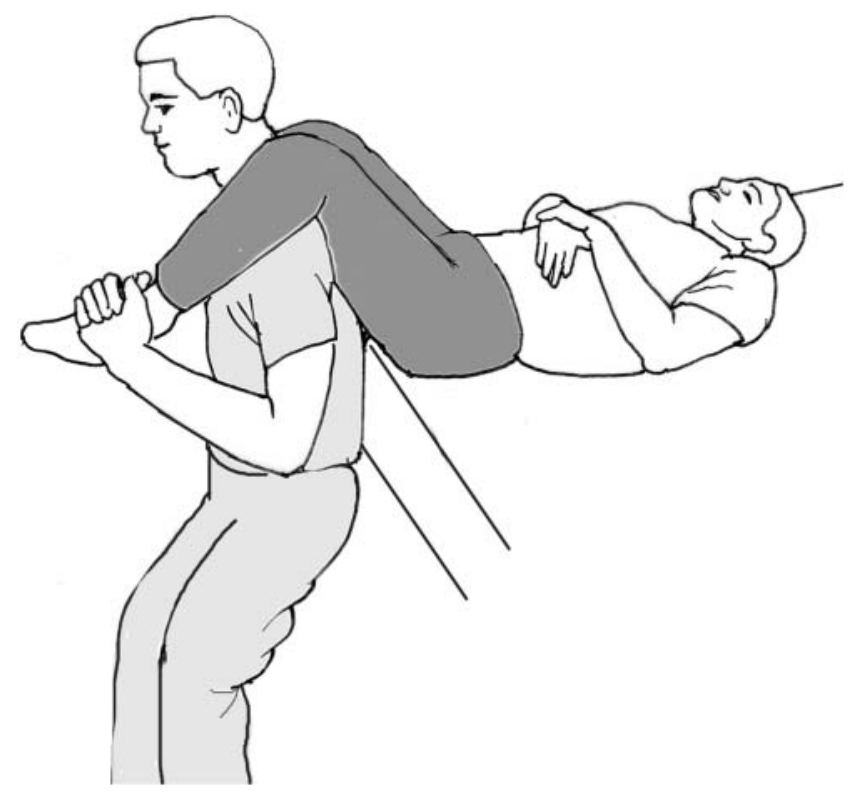

Figure 11. Piggyback method.?

treating physician to stay low and maintain stability while on the stretcher with the patient.

\section{Closed Reduction for Anterior Dislocations}

Closed reduction techniques for anterior dislocations require a slight variation in maneuvers, but treatment requires the same inline traction on the femur, hip extension, and external rotation. Unless reducing obturator-type dislocations, hip flexion is not possible as the femoral head rests on the anterior surface of the pelvis. We have not included illustrations of the reductions for anterior dislocations because they are performed with the same setup as posterior dislocations. 7,24,25,37,54

Allis Leg Extension Method: The patient is supine, and the physician may either climb on the stretcher or stand on the affected side. With an assistant stabilizing the patient's pelvis, the physician grasps the ipsilateral knee and applies inline traction until the hip is reduced. For pubic-type dislocations, hyperextension of the hip is required for reduction. ${ }^{7,24,40,54}$

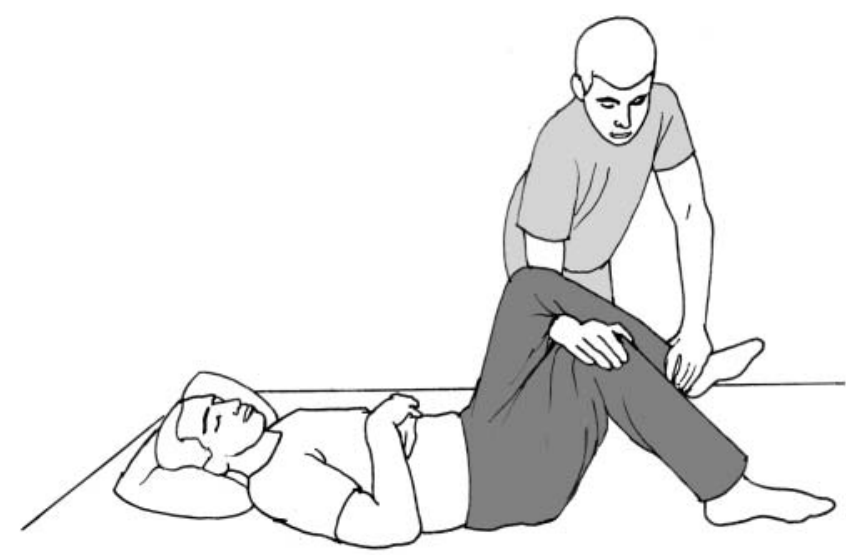

Figure 12. Tulsa technique/Rochester method/Whistler technique. $^{7}$

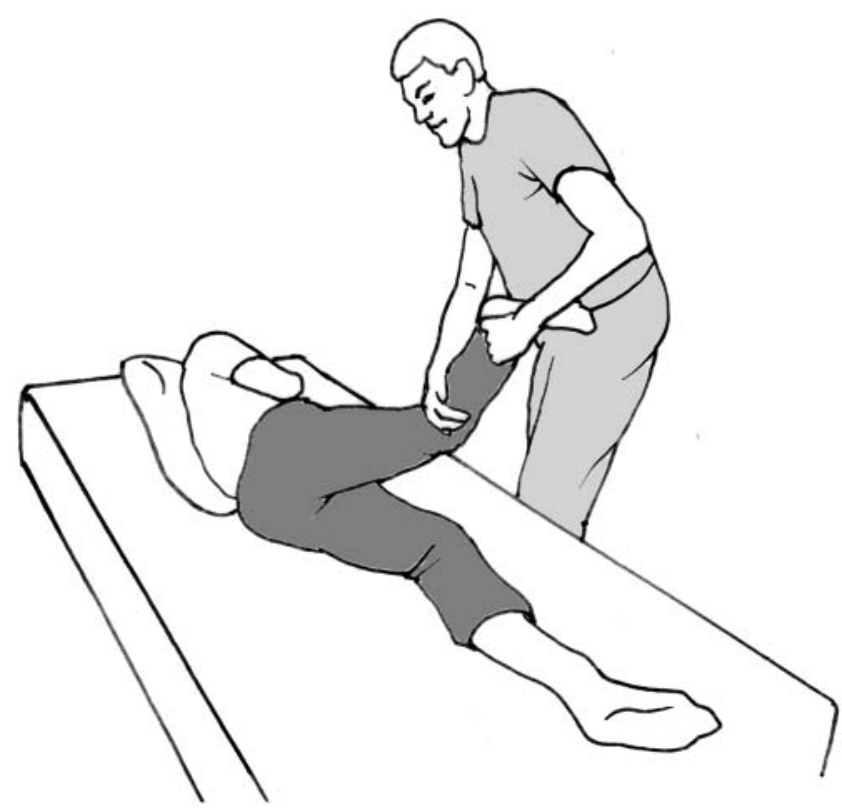

Figure 13. Skoff maneuver. ${ }^{7}$

Reverse Bigelow Method: The patient is supine, and the physician grasps the ipsilateral limb at the ankle with one hand and places the free hand behind the knee. Traction is applied in line with the deformity, and the hip is adducted, internally rotated, and extended. ${ }^{4,7}$ If climbing on the stretcher is not necessary, standing on the side of the stretcher is preferred for physician safety. 7,41

Lateral Traction Method: The patient is supine, and the assistant wraps a cloth around the ipsilateral inner thigh. The physician applies longitudinal force along the femur while the assistant pulls on the cloth to apply lateral traction as the hip is reduced. External rotation is used as needed to assist in reduction. ${ }^{4,46}$

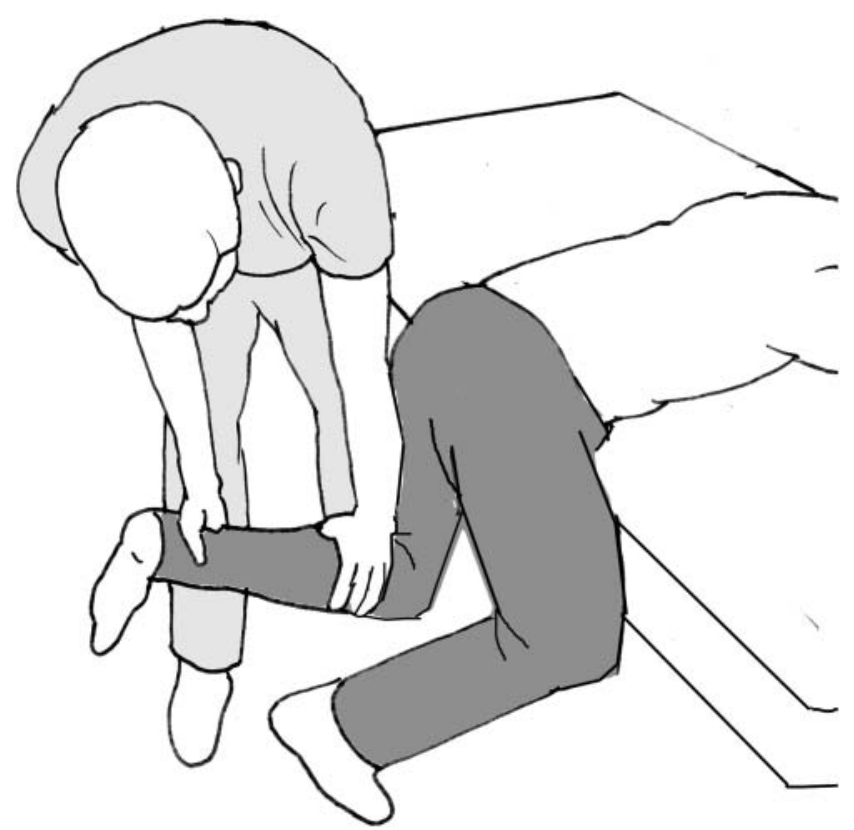

Figure 14. Stimson gravity maneuver. ${ }^{7}$ 


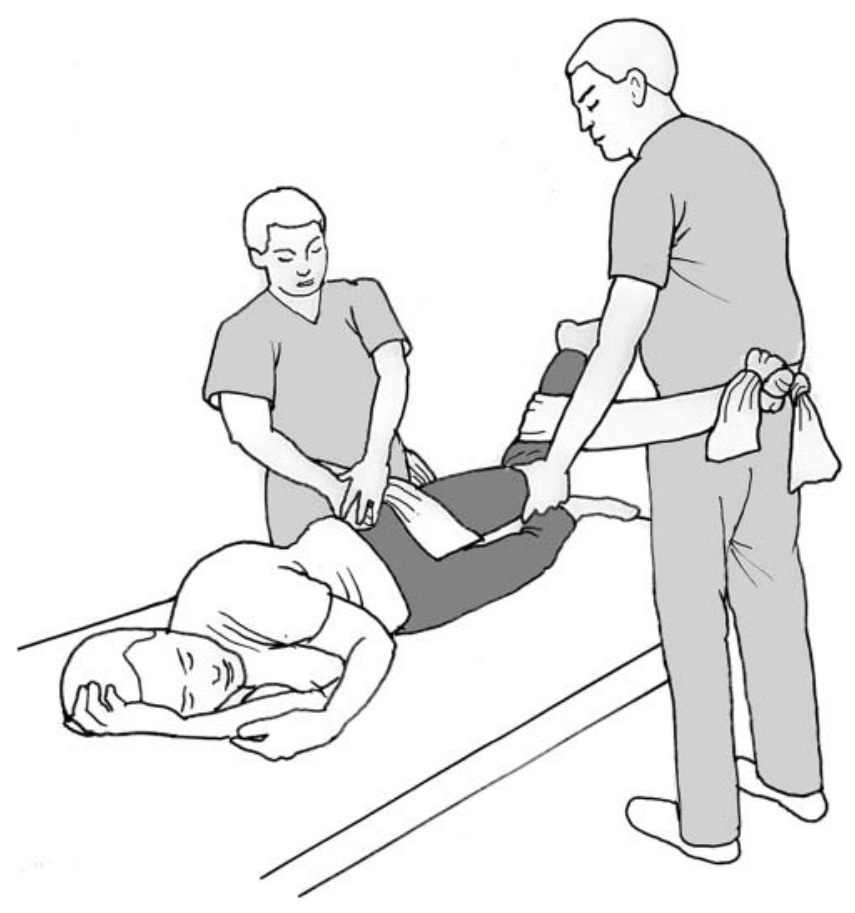

Figure 15. Traction-countertraction maneuver. ${ }^{7}$

Stimson Gravity Method: The patient is prone, with both hip and knees at $90^{\circ}$ of flexion over the edge of the stretcher. With an assistant stabilizing the pelvis, the physician holds the ipsilateral knee and ankle and applies a downward pressure to the limb distal to the knee until the hip is reduced. The physician can apply internal and external rotation to assist in reduction. Caution must be taken with this technique, as a sedated patient in the prone position must have his/ her airway continually monitored. Further, care must be taken to prevent the patient from falling off the stretcher. ${ }^{4,7,51}$ Because pubic-type dislocations are hyperextension injuries, reduction may not be achieved in such patients because hip flexion is not possible. ${ }^{7,23}$

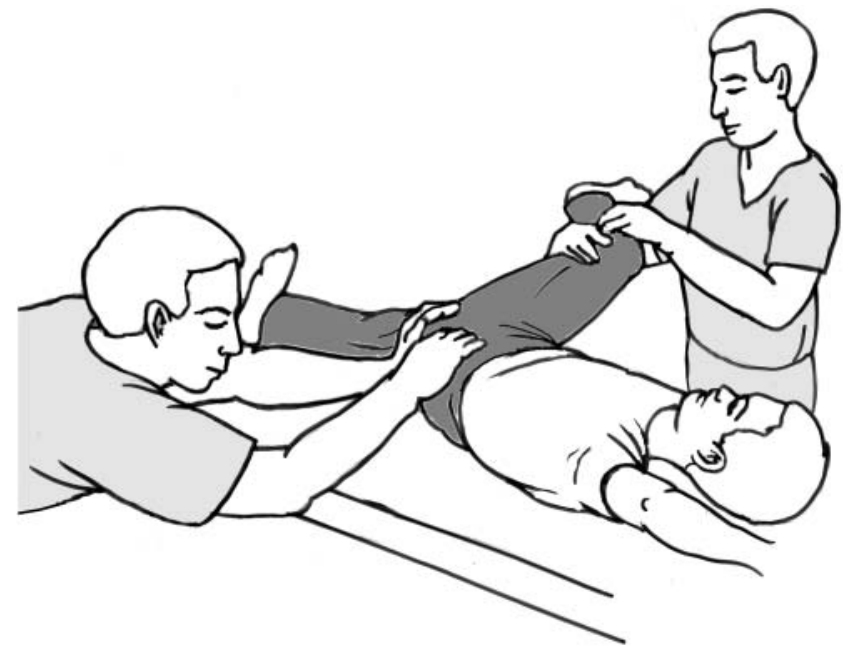

Figure 16. Flexion adduction maneuver. ${ }^{7}$

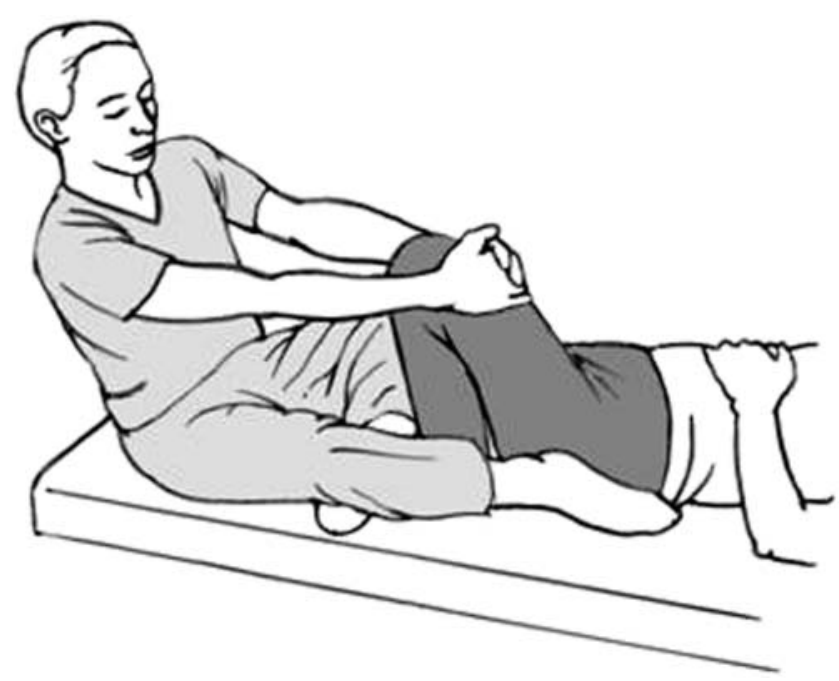

Figure 17. Foot-fulcrum maneuver. ${ }^{7}$

\section{Open Reduction}

If closed reduction fails, open reduction is indicated. Indications for open reduction include hips that have been dislocated for long periods of time, inability to achieve adequate sedation safely in the emergency department, dislocations that are irreducible, fractures of the femoral head or shaft, and persistent instability or redislocation following treatment. ${ }^{9,55}$ Irreducible posterior hip dislocations can be treated with the Kocher-Langenbeck approach in which the surgeon accesses the posterior structures of the acetabulum by demarcating the posterior superior iliac spine, greater trochanter, and femoral shaft. Anterior hip dislocations can be treated with the Smith-Petersen or Watson-Jones approach in which the surgeon accesses the anterior structures of the acetabulum by demarcating the anterior superior iliac spine, greater trochanter, and femoral shaft. In the case of a prosthetic dislocation, the previous surgical approach should be considered as well as surgeon familiarity and comfort with the approach. ${ }^{2,4,56}$

\section{SPECIAL CIRCUMSTANCES: CONSTRAINED LINERS AND DUAL-MOBILITY IMPLANTS}

As mentioned previously, constrained liners are used in patients with hip instability for various reasons such as recurrent dislocations with properly aligned components and soft tissue laxity. These implants are designed so that the polyethylene holds the femoral head in the hip socket by adding a strong constraint around the femoral head; the polyethylene conforms circumferentially around the femoral head, and the polyethylene is stabilized by a circular metal ring on top of the polyethylene. In cases of dislocation, reducing the femoral head through the constrained polyethylene can be difficult. Usually, in late dislocations, the polyethylene has worn so that reduction is possible. In a reduction attempt, the femoral head should be manually retracted to the acetabular cup and polyethylene through one of the techniques described previously. Usually, the femoral head will perch on the constrained rim. The physician should confirm the position with fluoroscopy and then place a medial force on the lateral aspect of the hip to try to force the femoral head back into the acetabulum. This procedure is described 

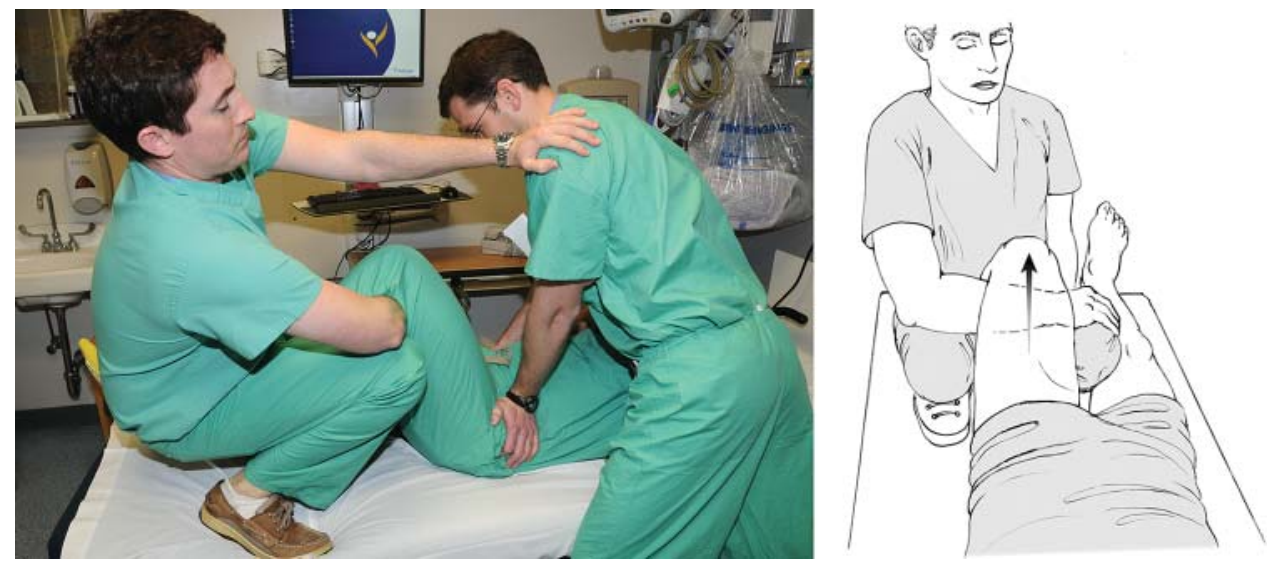

Figure 18. Waddell technique. ${ }^{7}$

in a 2012 case report that examined the successful post closed reduction outcome of a dual-mobility implant in an older individual with risk factors for dislocation. ${ }^{33}$

Dual-mobility implants were introduced in the United States in $2009 .{ }^{36}$ As noted previously, these implants have a small and a large articulation that can dissociate during dislocation or a reduction attempt. IPD can occur during a reduction attempt when the larger plastic femoral head catches on the acetabulum and dissociates from the smaller head, similar to a bottle-cap effect. To avoid this complication, first recognize the implant. Second, provide adequate sedation for complete muscular relaxation to facilitate the reduction. For posterior dislocations, internal rotation should be adequate to keep the femoral head from catching on the acetabular cup. For anterior dislocations, external rotation should be applied to keep the femoral head from contacting the acetabular liner. Finally, centricity of the femoral head should be confirmed in the postreduction x-rays. If the femoral head is eccentric in the acetabular cup, an IPD may have occurred. ${ }^{35}$

\section{COMPLICATIONS AFTER DISLOCATION}

Native dislocations have a higher rate of complication than prosthetic dislocations owing to the difference in force required for the event to occur. ${ }^{5,57,58}$ Because of the robust stability of the native hip joint, high-energy trauma (ie, motor vehicle collision) is required to cause a native hip dislocation and thus is commonly seen with polytrauma in up to $95 \%$ of patients. ${ }^{2,25,58,59}$ Conversely, because prosthetic hips are inherently less stable, they can be dislocated with low-energy forces. ${ }^{5,58}$ Adverse sequelae of native dislocations include femur and acetabular fractures, knee injuries, posttraumatic arthritis, sciatic nerve palsy, AVN, and heterotopic ossification. ${ }^{2-4,58-60}$

In native hip dislocations, femoral head fractures are less common than acetabular fractures, with an incidence rate of $5 \%-15 \% .^{3,4}$ Acetabular fractures most commonly occur from posterior dislocations resulting from trauma or closed reduction methods as the femoral head is brought hard against the posterior rim of the acetabulum. ${ }^{3,45,60}$ The incidence rate of acetabular fractures is as high as $70 \%{ }^{2,60} \mathrm{~A}$ broad range of ipsilateral knee injuries can be seen, especially following native dislocations. Significant knee injuries include effusion (37\%), bone bruise (33\%), and meniscal tears $(30 \%) .^{19,22,58}$ Posttraumatic arthritis represents the most common long-term sequela of simple native dislocation, with an incidence rate of approximately $20 \%$. $^{2,3,56,57,59} \mathrm{Sci}$ atic nerve palsy (peroneal component) is the most common neurologic structure damaged as a result of the femoral head stretching the nerve during dislocation or surgical scarring. ${ }^{2-5,26,60}$ The reported incidence rate of sciatic nerve palsy is $10 \%-15 \% .^{2,3,5,60}$ Because this injury is also time sensitive, delay in reduction may permanently impair nerve function, and patients may only see partial recovery. ${ }^{2,3,19,26}$ AVN can occur from prolonged dislocation following trauma or repeated attempts at reduction. ${ }^{2,19}$ The incidence rate of AVN following hip dislocation is approximately $2 \%-10 \%$, with in-

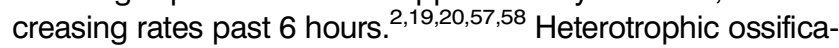
tion results in the presence of bone in soft tissue following repeated attempts at closed reduction. ${ }^{2,19}$ The incidence rate of heterotrophic ossification ranges from $2.8 \%-9 \%$. $^{3}$

Adverse sequelae of prosthetic hip dislocations are timesensitive emergencies but involve less-traumatic inciting events than native dislocations. 5,57,58 These complications include damage to the prosthesis, damage to the soft tissue leading to further instability, IPD, fracture of the femur, knee injury, and damage to surrounding neurovascular structures. Generally, however, prosthetic hip reduction is successful and leads to no further incidence of instability in the future..$^{2,3,19,58}$

\section{OUTCOMES AFTER DISLOCATION}

Because of the high energy nature of native hip dislocations, they are seldom seen without concurrent injury. 58,60,61 Minimizing the time to reduction is critical to prevent AVN of the femoral head. If the hip is reduced within 6 hours, the incidence of AVN drops significantly. ${ }^{2,4,19,56}$ A 2016 metaanalysis of AVN following traumatic hip dislocation found that if the limb is reduced after 12 hours, the odds of developing AVN is 5.6 times greater vs reduction prior to 12 hours. ${ }^{2,19,20,56,57} \mathrm{Re}$ current hip dislocations following an initial simple hip dislocation are rare, with an incidence rate of only $1 \%{ }^{2}$

Total hip replacement dislocations require additional management. While time to reduction does not play a role in AVN or chondrolysis as the joint has been replaced, minimizing the time to reduction is necessary because of muscular contracture. Following successful reduction of a prosthetic hip, a balance between immobilization and guarded mobilization must be achieved. ${ }^{4}$ Knee immobilizers or hip-abduction braces can be used to prevent patients 
from breaking the precautions associated with their surgical approach. ${ }^{8,62}$ In posterior dislocations, the brace should restrict flexion of the limb to $90^{\circ}$ and avoid internal rotation and adduction. In anterior dislocations, bracing and precautions should restrict all extension and external rotation of the limb. ${ }^{8}$ A disadvantage to external bracing is reduced patient compliance because of the inconvenience and unwieldy nature of these devices. However, an estimated two-thirds of patients can be successfully managed with closed reduction followed by external bracing. ${ }^{29}$ When closed reduction fails or instability persists, invasive methods include exchanging prosthetics, use of large femoral heads, use of dual-mobility implants, and/or use of constrained liners. ${ }^{29,36}$

\section{CONCLUSION}

With increasing rates of high-energy trauma and numbers of total hip replacements performed, the number of native and postreplacement hip dislocations will likely increase. Health providers must be familiar with best practices to diagnose and treat these patients. Patients with native and postoperative total hip replacement dislocations must receive careful diagnostic workup, and the treating physician must be well versed in the different ways to treat the injury and possible complications. Timely evaluation and treatment, including recognizing the potential complications, are necessary to offer the best outcome for the patient.

\section{ACKNOWLEDGMENTS}

Figures 4 through 18 were previously published in Waddell BS, Mohamed S, Glomset JT, Meyer MS, "A Detailed Review of Hip Reduction Maneuvers: A Focus on Physician Safety and Introduction of the Waddell Technique,"7 an open access article distributed under the terms of the Creative Commons Attribution Non-Commercial License that permits unrestricted noncommercial use, distribution, and reproduction in any medium, provided the original work is properly cited.

Dr Bradford Waddell is now affiliated with Hospital for Special Surgery, New York, NY. Dr Neil Duplantier is now affiliated with the Bone \& Joint Clinic, Gretna, LA.

The authors have no financial or proprietary interest in the subject matter of this article.

\section{REFERENCES}

1. Sculco PK, Lazaro LE, Su EP, et al. A vessel-preserving surgical hip dislocation through a modified posterior approach: assessment of femoral head vascularity using gadoliniumenhanced MRI. J Bone Joint Surg Am. 2016 Mar;98(6):475-483. doi: 10.2106/JBJS.15.00367.

2. Clegg TE, Roberts CS, Greene JW, Prather BA. Hip dislocationsepidemiology, treatment, and outcomes. Injury. 2010 Apr;41 (4):329-334. doi: 10.1016/j.injury.2009.08.007.

3. Beebe MJ, Bauer JM, Mir HR. Treatment of hip dislocations and associated injuries: current state of care. Orthop Clin North Am. 2016 Jul;47(3):527-549. doi: 10.1016/j.ocl.2016.02.002.

4. Sanders S, Tejwani N, Egol KA. Traumatic hip dislocation-a review. Bull NYU Hosp Jt Dis. 2010;68(2):91-96.

5. Brock G. The occasional posterior hip dislocation reduction. Can J Rural Med. 2015 Spring;20(2):65-70.

6. Specht EE. Congenital dislocation of the hip. West J Med. 1976 Jan;124(1):18-28.
7. Waddell BS, Mohamed S, Glomset JT, Meyer MS. A detailed review of hip reduction maneuvers: a focus on physician safety and introduction of the Waddell technique. Orthop Rev (Pavia). 2016 Mar 21;8(1):6253. doi: 10.4081/or.2016.6253.

8. D'Angelo F, Murena L, Zatti G, Cherubino P. The unstable total hip replacement. Indian J Orthop. 2008 Jul;42(3):252-259. doi: 10.4103/0019-5413.39667.

9. Zahar A, Rastogi A, Kendoff D. Dislocation after total hip arthroplasty. Curr Rev Musculoskelet Med. 2013 Dec;6(4):350356. doi: 10.1007/s12178-013-9187-6.

10. Yin TC, Wang JW, Lao ML, Chung HY. A simple technique for reducing posterior hip dislocation: the foot-fulcrum manoeuvre. Injury. 2010 Jun;41(6):665-667. doi: 10.1016/j.injury.2010.01.008.

11. Monma $H$, Sugita $T$. Is the mechanism of traumatic posterior dislocation of the hip a brake pedal injury rather than a dashboard injury? Injury. 2001 Apr;32(3):221-222. doi: 10.1016/ S0020-1383(00)00183-2.

12. Dargel J, Oppermann J, Brüggemann GP, Eysel P. Dislocation following total hip replacement. Dtsch Arztebl Int. 2014 Dec 22;111(51-52):884-890. doi: 10.3238/arztebl.2014.0884.

13. Maradit Kremers $\mathrm{H}$, Larson DR, Crowson CS, et al. Prevalence of total hip and knee replacement in the United States. J Bone Joint Surg Am. 2015 Sep 2;97(17):1386-1397. doi: 10.2106/JBJS.N.01141.

14. De Martino I, Triantafyllopoulos GK, Sculco PK, Sculco TP. Dual mobility cups in total hip arthroplasty. World J Orthop. 2014 Jul 18;5(3):180-187. doi: 10.5312/wjo.v5.i3.180.

15. U.S. Department of Transportation National Highway Traffic Safety Administration. Traffic safety facts: research note. 2014 motor vehicle crashes: overview. https://crashstats.nhtsa.dot .gov/Api/Public/ViewPublication/812246. Published March 2016. Accessed July 6, 2018.

16. Woo RY, Morrey BF. Dislocations after total hip arthroplasty. J Bone Joint Surg Am. 1982 Dec;64(9):1295-1306.

17. Kurtz S, Ong K, Lau E, Mowat F, Halpern M. Projections of primary and revision hip and knee arthroplasty in the United States from 2005 to 2030. J Bone Joint Surg Am. 2007 Apr;89 (4):780-785. doi: 10.2106/JBJS.F.00222.

18. Wetters NG, Murray TG, Moric M, Sporer SM, Paprosky WG, Della Valle CJ. Risk factors for dislocation after revision total hip arthroplasty. Clin Orthop Relat Res. 2013 Feb;471(2):410-416. doi: 10.1007/s11999-012-2561-7.

19. Dwyer AJ, John B, Singh SA, Mam MK. Complications after posterior dislocation of the hip. Int Orthop. 2006 Aug;30(4): 224-227. doi: 10.1007/s00264-005-0056-9.

20. Dreinhöfer KE, Schwarzkopf SR, Haas NP, Tscherne H. Isolated traumatic dislocation of the hip. Long-term results in 50 patients. J Bone Joint Surg Br. 1994 Jan;76(1):6-12.

21. Walden PD, Hamer JR. Whistler technique used to reduce traumatic dislocation of the hip in the emergency department setting. J Emerg Med. 1999 May-Jun;17(3):441-444. doi: 10.1016/ S0736-4679(99)00003-7.

22. Schmidt GL, Sciulli R, Altman GT. Knee injury in patients experiencing a high-energy traumatic ipsilateral hip dislocation. J Bone Joint Surg Am. 2005 Jun;87(6):1200-1204. doi: 10.2106/JBJS.D.02306.

23. Dawson I, van Rijn AB. Traumatic anterior dislocation of the hip. Arch Orthop Trauma Surg. 1989;108(1):55-57. doi: 10.1007/ BF00934160.

24. Polesky RE, Polesky FA. Intrapelvic dislocation of the femoral head following anterior dislocation of the hip. A case report. J Bone Joint Surg Am. 1972 Jul;54(5):1097-1098.

25. Toms AD, Williams S, White SH. Obturator dislocation of the hip. J Bone Joint Surg Br. 2001 Jan;83(1):113-115. doi: 10.1302/ 0301-620X.83B1.10289. 
26. Hillyard RF, Fox J. Sciatic nerve injuries associated with traumatic posterior hip dislocations. Am J Emerg Med. 2003 Nov;21(7):545-548. doi: 10.1016/j.ajem.2003.08.014.

27. Fairbairn KJ, Mulligan ME, Murphey MD, Resnik CS. Gas bubbles in the hip joint on CT: an indication of recent dislocation. Am J Roentgenol. 1995 Apr;164(4):931-934. doi: 10.2214/ ajr.164.4.7726051.

28. Mayer SW, Stewart JR, Fadell MF, Kestel L, Novais EN. MRI as a reliable and accurate method for assessment of posterior hip dislocation in children and adolescents without the risk of radiation exposure. Pediatr Radiol. 2015 Aug;45(9):1355-1362. doi: 10.1007/s00247-015-3317-9.

29. Werner BC, Brown TE. Instability after total hip arthroplasty. World J Orthop. 2012 Aug 18;3(8):122-130. doi: 10.5312/wjo.v3.i8.122.

30. Berry DJ, von Knoch $M$, Schleck CD, Harmsen WS. Effect of femoral head diameter and operative approach on risk of dislocation after primary total hip arthroplasty. $J$ Bone Joint Surg Am. 2005 Nov;87(11):2456-2463. doi: 10.2106/JBJS. D.02860.

31. Hummel MT, Malkani AL, Yakkanti MR, Baker DL. Decreased dislocation after revision total hip arthroplasty using larger femoral head size and posterior capsular repair. J Arthroplasty. 2009 Sep;24(6 Suppl):73-76. doi: 10.1016/j.arth.2009.04.026.

32. Howie DW, Holubowycz OT, Middleton R; Large Articulation Study Group. Large femoral heads decrease the incidence of dislocation after total hip arthroplasty: a randomized controlled trial. J Bone Joint Surg Am. 2012 Jun 20;94(12):1095-1102. doi: 10.2106/JBJS.K.00570.

33. Sonohata M, Waewsawangwong W, Goodman SB. Successful closed reduction of a dislocated constrained total hip arthroplasty: a case report and literature review. Open Orthop J. 2012;6:211-214. doi: 10.2174/1874325001206010211.

34. Birdwell S, Wilke E. Closed reduction of constrained total hip arthroplasty in the ED. J Emerg Med. 2011 Feb;40(2):162-166. doi: 10.1016/j.jemermed.2007.10.069.

35. Waddell BS, De Martino I, Sculco T, Sculco P. Total hip arthroplasty dislocations are more complex than they appear: a case report of intraprosthetic dislocation of an anatomic dual-mobility implant after closed reduction. Ochsner J. 2016 Summer;16(2):185-190.

36. De Martino I, D'Apolito R, Waddell BS, McLawhorn AS, Sculco PK, Sculco TP. Early intraprosthetic dislocation in dual-mobility implants: a systematic review. Arthroplast Today. 2017 Feb 5;3 (3):197-202. doi: 10.1016/j.artd.2016.12.002.

37. Kobayashi $H$, Nakashima $Y$, Yamamoto $T$, et al. Late anterior dislocation due to posterior pelvic tilt in total hip arthroplasty. Open Orthop J. 2016 Jun 22;10:206-212. doi: 10.2174/ 1874325001610010206.

38. Mudrick CA, Melvin JS, Springer BD. Late posterior hip instability after lumbar spinopelvic fusion. Arthroplast Today. 2015 Jun 19;1(2):25-29. doi: 10.1016/j.artd.2015.05.002.

39. Frymann SJ, Cumberbatch GL, Stearman AS. Reduction of dislocated hip prosthesis in the emergency department using conscious sedation: a prospective study. Emerg Med J. 2005 Nov;22(11):807-809. doi: 10.1136/emj.2003.011809.

40. Allis OH. The Hip. Philadelphia, PA: Dorman Printer; 1895:14-26.

41. Bigelow H. On dislocation of the hip. Lancet. 1878 Jun;111 (2859):860-862. doi: 10.1016/S0140-6736(02)43952-9.

42. Lefkowitz M. A new method for reduction of hip dislocations. Orthop Rev. 1993 Feb;22(2):253-256.

43. Hendey GW, Avila A. The Captain Morgan technique for the reduction of the dislocated hip. Ann Emerg Med. 2011 Dec;58 (6):536-540. doi: 10.1016/j.annemergmed.2011.07.010.
44. Schafer SJ, Anglen JO. The East Baltimore Lift: a simple and effective method for reduction of posterior hip dislocations. $J$ Orthop Trauma. 1999 Jan;13(1):56-57. doi: 10.1097/00005131199901000-00013.

45. Howard CB. A gentle method of reducing traumatic dislocation of the hip. Injury. 1992;23(7):481-482. doi: 10.1016/0020-1383 (92)90069-5.

46. Nordt WE 3rd. Maneuvers for reducing dislocated hips. A new technique and a literature review. Clin Orthop Relat Res. 1999 Mar;(360):260-264.

47. Marya SK, Samuel AW. Piggy back technique for relocation of posterior dislocation of the hip. Injury. 1994 Sep;25(7): 483-484.

48. Vosburgh CL, Vosburgh JB. Closed reduction for total hip arthroplasty dislocation. The Tulsa technique. J Arthroplasty. 1995 Oct;10(5):693-694.

49. Stefanich RJ. Closed reduction of posterior hip dislocation: the Rochester method. Am J Orthop (Belle Mead NJ). 1999 Jan;28 (1):64-65.

50. Skoff HD. Posterior hip dislocation, a new technique for reduction. Orthop Rev. 1986 Jun;15(6):405-409.

51. Stimson LA. A Practical Treatise on Fractures and Dislocations. New York, NY and Philadelphia, PA: Lea Brothers \& Co.;1905. Retrieved from the Library of Congress. https://archive.org /details/practicaltreat00stim. Accessed July 17, 2018.

52. Dahners LE, Hundley JD. Reduction of posterior hip dislocations in the lateral position using traction-countertraction: safer for the surgeon? J Orthop Trauma. 1999 Jun-Jul;13(5):373-374. doi: 10.1097/00005131-199906000-00010.

53. Bassi JL, Ahuja SC, Singh H. A flexion adduction method for the reduction of posterior dislocation of the hip. $J$ Bone Joint Surg Br. 1992 Jan;74(1):157-158.

54. Chadha M, Agarwal A, Singh AP. Traumatic anterior dislocation of the hip joint with posterior acetabular wall fracture. Acta Orthop Belg. 2005 Feb;71(1):111-114.

55. Karthik K, Sundararajan SR, Dheenadhayalan J, Rajasekaran S. Incongruent reduction following post-traumatic hip dislocations as an indicator of intra-articular loose bodies: a prospective study of 117 dislocations. Indian J Orthop. 2011 Jan;45(1):33-38. doi: 10.4103/0019-5413.73650.

56. Tornetta P 3rd, Mostafavi HR. Hip dislocation: current treatment regimens. J Am Acad Orthop Surg. 1997 Jan;5(1):27-36.

57. Kellam P, Ostrum RF. Systematic review and meta-analysis of avascular necrosis and posttraumatic arthritis after traumatic hip dislocation. J Orthop Trauma. 2016 Jan;30(1):10-16. doi: 10.1097/BOT.0000000000000419.

58. Masiewicz S, Johnson DE. Dislocation, Hip (Femur), Posterior. StatPearls [Internet]. Treasure Island (FL): StatPearls Publishing; 2018 Jan. https://www.ncbi.nlm.nih.gov/books/NBK459319/. Updated October 21, 2017. Accessed July 17, 2018.

59. Sahin V, Karakaş ES, Aksu S,Atlihan D, Turk CY, Halici M. Traumatic dislocation and fracture-dislocation of the hip: a long-term follow-up study. J Trauma. 2003 Mar;54(3):520-529. doi: 10.1097/01.TA.0000020394.32496.52.

60. Alonso JE, Volgas DA, Giordano V, Stannard JP. A review of the treatment of hip dislocations associated with acetabular fractures. Clin Orthop Relat Res. 2000 Aug;(377):32-43.

61. Hak DJ, Goulet JA. Severity of injuries associated with traumatic hip dislocation as a result of motor vehicle collisions. J Trauma. 1999 Jul;47(1):60-63.

62. Cooper HJ, Walters BL, Rodriguez JA. Anatomy of the hip capsule and pericapsular structures: a cadaveric study. Clin Anat. 2015 Jul;28(5):665-671. doi: 10.1002/ca.22539. 